\title{
Egunkaria: 15 años de injusticia
}

institucionales.us.es/ambitos/

\section{Jose Mari Pastor González \\ Universidad del País Vasco}

Eran las cuatro de la mañana del 20 de febrero de 2003 cuando sonó el teléfono de casa. La mujer de un excompañero de trabajo llamaba para informarnos de que la Guardia Civil había entrado en la sede central del diario Euskaldunon Egunkaria con una orden del juez Juan del Olmo para registrar los locales. El director y otros cargos responsables del periódico habían sido detenidos en sus domicilios. La acusación del juez para justificar la operación era de extrema gravedad. Según él, Egunkaria era

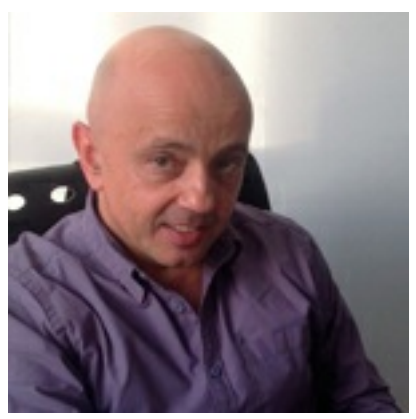
un instrumento de ETA, y tenía "un lugar en la estructura de la banda y unos enlaces determinados para recibir las directrices de la misma".

Aquella madrugada la Guardia Civil se llevó detenidas a Madrid, en régimen de incomunicación, a un total de diez personas. Entre ellas se encontraban Joan Mari Torrealdai, presidente del Consejo de Administración de Egunkaria; Iñaki Uria, consejero delegado de Egunkaria SA y exdirector de Egunkaria; Pello Zubiria, primer director del diario; Txema Auzmendi, miembro del Consejo de Administración de Egunkaria, periodista y jesuita y, por último, Xabier Oleaga, quien fuera durante un tiempo subdirector del diario. La acusación que pesaba sobre ellos -ser parte del engranaje de ETA- no tenía ninguna base, según el contenido de la sentencia que los jueces del caso Egunkaria dictaminaron en el juicio posterior. Todos los acusados fueron absueltos el año 2010 -la petición fiscal era de penas que oscilaban entre los 12 y 14 años de cárcel-. Para entonces habían pasado ya siete años y no había marcha atrás: Egunkaria estaba cerrado para siempre.

Se han cumplido ya quince años desde que aquella orden judicial obligó a cerrar el único periódico que existía en lengua vasca. Centenares de personas -muchas, representantes de los ámbitos sociales, culturales y políticos del País Vasco- se reunieron el pasado 20 de febrero en el parque cultural Martin Ugalde de Andoain, donde se encontraba la antigua sede del diario, para expresar su repulsa a aquella injusta medida cuyas consecuencias no llegaron a ser del todo reparadas.

El caso Egunkaria es un ejemplo que ilustra las arbitrariedades o abusos que pueden sufrir los medios de comunicación por parte del poder. El periódico Egunkaria -en lengua vasca, El Diario- nació el seis de diciembre de 1990. Con ello se cumplió el sueño anhelado durante tantos años por la comunicad vascohablante: la publicación de un diario en su lengua. El euskara contaba ya con radio y televisión; le faltaba todavía el soporte de la prensa diaria para normalizar, en cierta medida, su presencia en los medios de comunicación. El único diario en vasco publicado con anterioridad había sido Eguna (1937) pero tuvo una vida efímera, ya que debió interrumpir su labor informativa con la entrada de 
las tropas franquistas en Bilbao.

Fueron necesarias más de cinco décadas para que se volviera a publicar otro periódico en euskara. El proyecto pudo crearse gracias a la ayuda desinteresada de cientos y cientos de personas, muchas de ellas pertenecientes al mundo de la cultura y colectivos sociales y otras anónimas. La compra de acciones -la mayoría de ellas de un valor de 150 eurosposibilitó la adquisición del capital necesario para el nacimiento del diario. Egunkaria tuvo una vida fructífera en sus más de doce años de existencia y se convirtió en un medio de referencia para la comunidad vascohablante. Según los datos de la empresa CIES, en su último año contaba con 50.000 lectores. Dos días después de su cierre decenas de miles de personas se concentraron en San Sebastián para protestar por la decisión del juez Del Olmo. Fue la mayor manifestación jamás hecha en la capital guipuzcoana.

El cierre de Egunkaria puso en evidencia que la libertad de expresión no está del todo libre de los ataques que se puedan producir desde las instancias del poder; que esa persecución puede suceder en el corazón de la Unión Europea. Y es que, en este caso, las personas perjudicadas por esa injusta decisión eran miembros de una comunidad política de derecho cuyos principios son la bases que rigen la convivencia ciudadana y sirven de referencia como estándares democráticos para otros estados del mundo.

La sentencia que absolvió a los acusados constató que el cierre del diario había sido un atropello contra la libertad de prensa: "Por último, un juicio de ponderación entre la libertad de prensa que fue sacrificada, o suspendida singularmente, y los fines de prevención de la supuesta reiteración delictiva que se declaraban pone de manifiesto que dichos fines podían haberse conseguido usando otras posibilidades alternativas de intervención cautelar que no implicaran la interrupción de la actividad informativa, de la elaboración, impresión y distribución del diario. Sobre todo cuando, según la prueba practicada, el análisis de la línea informativa permitía descartar que el periódico fuera instrumento para la comisión de delitos o soporte de actividad criminal alguna". También demostró que no existía conexión alguna entre Egunkaria y ETA: "Tampoco se ha acreditado ni directa ni indirectamente que el periódico Euskaldunon Egunkaria haya defendido los postulados de la banda terrorista, haya publicado un solo artículo a favor del terrorismo o de los terroristas ni que su línea editorial tuviese siquiera un sesgo político determinado, esto último, además, no sería delictivo".

Quedaban lejanas algunas declaraciones realizadas la horas posteriores al cierre del diario, impregnadas de cinismo, mala fe o, en el mejor de los casos, ignorancia. El ministro del Interior Ángel Acebes (PP) llegó a afirmar: "Se trata de una operación en defensa y protección de los derechos y de las libertades de los vascos, de su cultura, de su pensamiento, y de la expresión de su lengua en libertad". Esas declaraciones me hicieron recordar las palabras del actor valenciano Ovidi Montllor (1942-1995): "Hay gente a la que no le gusta que se hable, se escriba o se piense en catalán. Es la misma gente a la que no le gusta que se hable, se escriba y se piense". Esta cita habría sido la respuesta adecuada a la afirmación del ministro Acebes; eso sí, con un ligero cambio: sustituir la palabra catalán por euskara.

Lo sucedido con Egunkaria tenía un precedente: el cierre, cinco años antes, del diario Egin y de su emisora de radio por orden del juez Baltasar Garzón. En el juicio posterior los jueces no apreciaron ninguna razón de peso que justificara la toma de una decisión de 
tamaño calibre, tal y como harían después en el caso Egunkaria. El dosier con la causa contra el único diario en euskara llegó también a manos de Garzón, pero el juez que ordenó precintar Egin consideró que aquellas acusaciones carecían de fundamento para iniciar el proceso contra Egunkaria. Fue entonces cuando el juez Del Olmo se hizo cargo del asunto y se convirtió en uno de los principales protagonistas de aquel atropello judicial.

El cierre del periódico puso en entredicho la división de poderes en el Estado español. Estas dudas ya afloraron cuando el 15 de julio de 1998 Garzón cerró Egin y el presidente José María Aznar (PP) espetó: “¿Alguien pensaba que no nos íbamos a atrever a cerrar Egin?". Esas palabras sugirieron a más de uno que Aznar, además de ser presidente del gobierno, tenía la potestad de erigirse también como máxima autoridad del poder judicial o de que la decisión de cerrar el diario pudiera haber sido tomada por el gobierno, tal y como indicó Julio Anguita, coordinador general de Izquierda Unida.

La clausura de Egunkaria se produjo en un contexto político determinado. EI PP contaba con mayoría absoluta y eso le dejaba las manos libres para gobernar sin el apoyo de los nacionalismos periféricos. Los atentados de ETA continuaban, y el discurso construido por Garzón, reflejado en el lema Todo es ETA, era un instrumento inestimable para criminalizar a la izquiera abertzale y a cualquier independentista. Aunque no aprobara la violencia, el hecho de ser partidario de la secesión o de la autodeterminación lo convertía automáticamente en sospechoso, ya que compartía el objetivo final de ETA.

Las razones esgrimidas para cerrar el periódico se sitúan dentro de esa lógica. Este diario nunca ocultó que su ámbito natural se circunscribía al territorio de Euskal Herria o País del Euskara, es decir, al espacio lingüístico propio de la lengua vasca: Álava, Bizkaia, Gipuzkoa y Navarra dentro de los límites del Estado español y Labort, Baja Navarra y Sola al otro lado de la frontera. Egunkaria tampoco negó que era un periódico nacional y que el adjetivo nacional se refería al territorio antes mencionado. Pero, de igual manera, su línea editorial nunca justificó la violencia de ETA. Como muestra, un botón: justo doce días antes del cierre del diario ETA acabó con la vida de Joseba Pagazaurtundua en Andoain. Esa misma semana Martxelo Otamendi, director del periódico, escribió en su artículo de opinión dominical que la violencia no tenía cabida para impulsar las reivindicaciones políticas vascas. Diez días después Otamendi era detenido bajo la acusación de... jestar relacionado con ETA!

En una de las charlas informativas a las que asistí tras el cierre del diario me vi en la obligación de mencionar el contenido de aquel artículo para dejar claro que Egunkaria no estaba supeditado a ETA. Fue en la Universidad de Valencia. Un periodista presente en el acto me preguntó qué opinión tenía Egunkaria sobre la violencia de ETA. Entonces leí el texto que nuestro director había escrito unas pocas semanas antes. “¿Cómo va a escribir esto un periodista que está a las órdenes de ETA?", pregunté al periodista. Este se marchó antes de que acabara el acto. "Ya ha conseguido el titular que quería", me dijo un profesor de aquella universidad que, como yo, tomaba parte en el mismo.

El titular me llegó al cabo de unos días por fax, desde Valencia. Era el siguiente: "La Universidad con los proetarras de Egunkaria". El autor nos dedicaba toda clase de epítetos. Pastor era "periodista" -entre comillas, pese a que me licencié en Periodismo en 1985 y llevo trabajando o colaborando en medios de comunicación desde el año 1981- y 
Egunkaria "el diario proetarra", "el panfleto separatista" o "el libelo próximo a Batasuna". El nombre del juez que había emitido el auto no era Juan Del Olmo, sino Guillermo Ruiz Polanco. Se trataba de todo un texto digno de ser mostrado en la facultad para enseñar cuál debería ser la labor del periodista y su compromiso ético, así como la diferencia entre los géneros de información y de opinión.

Aunque la actitud irrespetuosa de aquel periodista y la ideología subyacente en sus palabras podrían ser calificadas como extremistas e incluso grotescas, no deberían ocultar la triste realidad: la crítica de los medios de comunicación al cierre del diario fue por lo general, y en los pocos casos en que se produjo, más bien tibia. Algunos mostraron cierta cautela sobre el procedimiento de clausura, pero nada más. Según el juez, ETA estaba relacionada con el periódico. ¿Por qué criticar el cierre? Muchos no solo no denunciaron ese ataque a la libertad de expresión, sino que también dudaron de las denuncias de torturas de los detenidos. El periodista de un diario de Madrid me contestó lo siguiente cuando afirmé en la ETB (Televisión Vasca) que creía a Otamendi cuando este decía que había sido torturado: "Tú le crees a Martxelo porque eres su amigo".

La sentencia del caso, si bien no confirmó explícitamente esos casos de tortura, dejó entrever que era posible que hubieran sucedido, y afirmó que la incomunicación de los detenidos no fue supervisada correctamente: "En la valoración de las declaraciones de los procesados tiene especial relevancia que las denuncias de estos sobre malos tratos y torturas sufridos durante la detención incomunicada -que fueron relatadas con detalle en la vista oral y antes ante el instructor y objeto de denuncia en los tribunales- son compatibles con lo expuesto en los informes médico-forenses emitidos tras ser reconocidos en el centro de detención, si bien el Tribunal no puede llegar a conclusiones jurídico penalmente relevantes sobre el particular salvo constatar que no hubo un control judicial suficiente y eficiente de las condiciones de la incomunicación".

Sí, muy pocas voces se alzaron para condenar ese ataque a la libertad de expresión. Es fácil criticar hechos similares cuando suceden lejos -en Turquía, por ejemplo-, pero ¿qué decir cuando suceden en tu propio país? Fuera del País Vasco, fue en Cataluña donde la clausura de Egunkaria provocó mayores protestas. El cierre despertó una ola de solidaridad ciudadana e institucional con el apoyo de diferentes sectores de la sociedad. El día de Sant Jordi de 2003, un mes después del cierre del diario, publicaron una edición del periódico en catalán -Egunkaria endavant- y repartieron 30.000 ejemplares del mismo,

Un año después, en vísperas del Día Internacional de la Libertad de Prensa, la portavoz del Gobierno Vasco, Miren Azkarate (PNV), mencionó el caso de Egunkaria: "Estamos ante una situación que es muy especial en Europa, porque en democracia no es normal el cierre de medios de comunicación sin ningún tipo de juicio previo". Iñaki Uria todavía estaba encarcelado, sin sentencia alguna. Ya llevaba más de un año de prisión preventiva.

El cierre de Egunkaria fue un fuerte golpe al periodismo en euskara pero no consiguió hacerlo enmudecer. El día siguiente al cierre sus periodistas publicaron Egunero, con este titular: Cerrado, pero no callado. Ese diario se editó durante cuatro meses hasta que el 21 de junio nació Berria. Han pasado quince años desde aquella injusticia, y no ha habido reparación al respecto. Sea como sea, no pudieron frustrar nuestro sueño. 


\section{BREVE SEMBLANZA DEL AUTOR:}

Jose Mari Pastor es profesor del Departamento de Periodismo de la Facultad de Ciencias Sociales y de la Comunicación de la Universidad del País Vasco. Desde principios de la década de los ochenta y hasta la actualidad ha trabajado o colaborado en diversos medios de comunicación, como Anaitasuna, Egunon, EITB (Radio Televisión Vasca) Egunkaria y Berria.

\section{Versión en euskera:}

2003ko otsailaren 20ko goizeko laurak pasatuak ziren gure etxeko telefonoak jo zuenean. Kazetari eta lankide ohi baten emaztea zen. Zerbait larria gertatzen ari zela jakinarazi zigun: Guardia Zibila Euskaldunon Egunkaria-ren egoitzan zen, Auzitegi Nazionaleko epaile Juan del Olmo jaunaren aginduz, hura miatzeko. Era berean, institutu armatuko kideek hedabideko zuzendari eta beste arduradun batzuen etxeetan sartu, eta haiek atxilotu zituzten. Del Olmoren arabera, Egunkaria ETAren tresna zen eta "leku bat zuen taldearen egituran, eta bitarteko jakin batzuk haren aginduak jasotzeko".

Egun hartan Guardia Zibilak hamar lagun eraman zituen Madrilera, inkomunikaturik. Euren artean hauek zeuden, besteak beste: Martxelo Otamendi, orduko zuzendaria; Joan Mari Torrealdai Egunkaria-ko Administrazio Kontseiluko burua, Iñaki Uria Egunkaria SAko kontseilari ordezkaria eta Egunkaria-ko zuzendaria izandakoa, Pello Zubiria, Egunkariako lehen zuzendaria izana; Txema Auzmendi, Egunkariako Administrazio Kontseiluko kidea, kazetaria eta jesuita, eta Xabier Oleaga, Egunkariako zuzendariorde ohia. Akusazioa: ETArekin loturak izatea. Epaiketan frogatuko zenez, akusazio horiek ez zuten inolako oinarririk. Epaitutako guztiak errugabetu egin zituzten 2010ean -12 eta 14 urte bitarteko zigor eskaera zegoen bakoitzarentzat-, eta kasua artxibatu egin zen. Zazpi urte pasatu ziren, eta egunkaria itxia zen betiko. Ez zegoen atzera bueltarik.

Aurten hamabosgarren urtea bete da euskarazko egunkari bakarra itxi zutenetik. Horren harira, otsailaren 20an ehunka lagun elkartu ziren Andoaingo Martin Ugalde kultur parkean (Gipuzkoa), Euskaldunon Egunkaria kokatuta zegoen lekuan bertan. Euskal Herriko gizarte, kultura eta informazioaren munduko hainbat ordezkarik bat egin zuten bidegabekeria hura salatu eta iragan hari eta geroari buruzko hausnarketa egiteko.

Egunkaria auzia baliagarria da botereak hedabideen kontra bultza ditzakeen eraso, gehiegikeria eta arbitrarietateez jabetzeko. Egunkaria 1990. urteko abenduaren 6an jaio zen. Horrela, urteetan izandako ametsa bete genuen: euskaldunok euskarazko egunkaria izatea. Euskarak bazituen irratia eta telebista; egunkaria baino ez zuen falta. Ordura arte kazeta bakarra argitaratu zen euskara hutsez. Eguna egunkaria 1937an kaleratu zen zenbait hilabetez, baina argitalpena eten egin zen Francoren tropak Bilbon sartu eta gero.

Bost hamarkada baino gehiago behar izan ziren euskarak berriro ere egunkari bat izateko. Horretarako, gizarte eta kultura arloko hainbat eragile eta lagunen laguntza izan zuen. Milaka eta milaka pertsonak akzioak erosi zituzten -gehienak 150 eurokoak- hedabidea sortu ahal izateko kapitala biltze aldera. Egunkariak ibilbide emankorra egin zuen hamabi 
urte pasatxo horretan eta erreferentzia bihurtu zen herritar euskaldunentzat. Bere azken urtean 50.000 irakurle zituen, CIES enpresaren datuen arabera. Egunkaria itxi eta bi egunera dozenaka mila lagun elkartu ziren Donostiako kaleetan Del Olmo epailearen erabakia gaitzesteko. Gipuzkoako hiriburuan inoiz izan den manifestazio jendetsuena izan zen.

Egunkariaren itxierak agerian utzi zuen prentsa askatasuna ez dagoela erasoetatik guztiz libre, Europako Batasunean bertan ere gerta zitezkeela jazarraldiak. Izan ere, kasu honetan munduari demokraziaren oinarriak eta arau estandarrak erakutsi eta ezartzen dizkion gune europarreko kazetari eta irakurleek pairatu zituzten erabaki bidegabe horren ondorioak. Horixe azaldu zuen Egunkariaren kasuko akusatuak absolbitu zituen epaiak. Horren arabera, prentsa askatasuna "sakrifikatu" egin zen Egunkaria ixtean. Ez zegoen neurri hori hartzeko oinarririk. Ustezko delituak egiten segitzen ez uzteko beste aukera batzuk bazeudela nabarmendu zuten epaileek, "jarduera informatiboa, egunkaria egitea, inprimatzea eta banatzea etetea eragingo ez zutenak. Batez ere, egin den azterketaren ondorioz ildo informatiboaren analisiak ahalbidetzen duenean egunkaria delituak egiteko edo ezelango jarduera kriminala egiteko tresna zela baztertzea". Epaiak argi utzi zuen ez zegoela Egunkariaren eta ETAren arteko loturarik. Hala, Del Olmo epaileak hedabidea ixteko emandako aginduak funtsik ez zuela frogatu zuen: "Ez da frogatu, ez zuzenean ez zeharka, Euskaldunon Egunkaria kazetak talde terroristaren postulaturik defendatu duenik, terrorismoaren edo terroristen aldeko artikulu bat bera ere argitaratu duenik, ezta haren ildo editorialak joera politiko zehatz bat zuenik ere".

Euskararen normalkuntzarako baliabide ezin egokiagoa izan zena itxi zuten, erabaki hura defendatzeko inolako argudio sendorik gabe. Hori barik, ezjakintasun, zinismo eta maltzurkeria hitzak entzun ziren. Ángel Acebes Barne ministroa (PP) hau esatera ausartu zen: "Euskaldunen eskubide eta askatasunak, haien kultura, pentsamendua eta haien hizkuntzaren adierazpen librea defendatzeko eta babesteko operazioa izan da". Hori entzunda, Ovidi Montllor aktore valentziarrak (1942-1995) behinola esaniko hitzak etorri zitzaizkidan gogora: "Badago jendea, gustukoa ez duena katalanez hitz egin, idatz edo pentsa dadila. Hitz egin, idatz edo pentsa dadila gustukoa ez duen jende bera da». Katalana hitzaren ordez euskara hitza jarri eta berdin-berdin erabil liteke aipua Acebes jaunaren jarrera salatzeko.

Egunkariaren auzian gertatuak bazuen aurrekaririk, baina. Bost urte lehenago Egin egunkaria eta Egin Irratia ixtea agindu zuen Baltasar Garzón epaileak. Erabaki hura guztiz bidegabea izan zela erabakiko zuten epaileek gero, Egunkariaren auzian bezalaxe. Euskarazko egunkari bakarraren kasua Garzonen eskuetara iritsi zen, baina Egin itxi zuenak ez zuen arrazoi zantzurik atzeman guardia zibilek pasatutako txostenean Egunkariarekin berdin jokatzeko. Juan del Olmo epaileak bere gain hartu zuen kasua. Bera izan zen eraso judizial haren protagonista nagusietako bat.

Egunkariaren itxierak auzitan jarri zuen Espainiako botereen funtzionamendua eta horien arteko banaketa. Botere exekutiboaren, legegilearen eta judizialaren arteko bereizketa lainotsua zela frogatua zen lehenago, 1998ko uztailaren 15ean Garzonek Egin zarratu zuenean. "Inork uste al zuen ez ginela Egin ixtera ausartuko?", adierazi zuen Espainiako presidente Jose Maria Aznarrek (PP). Botere exekutiboaren buruak botere judizialaren ordezkari goren gisa ere irudikatu zuen bere burua, lotsatu egin barik, Egin ixteko erabakia 
epaileen eta gobernuaren artean hartua izan balitz bezala. Horixe iradoki zuen Julio Anguita IUko koordinatzaile nagusiak: itxiera "Gobernuaren erabakia" izan zela ulertarazi zuten Aznarren hitzek.

Egunkariaren itxiera testuinguru jakin batean kokatu behar da. Alderdi Popularrak gehiengo absolutua zuen Espainiako Kongresuan. Esku libreak zituen agintzeko, eta ez zuen nazionalismo periferikoen sostengurik behar. ETAren indarkeriak bizirik segitzen zuen eta haren inguruan Garzon epaileak sortu eta hedatutako Dena ETA da leloa tresna ezin egokiagoa zen ezker abertzalea eta sektore independentistak oro kriminalizatzeko, ETAren jarduerarekin bat etorri edo ez. ETA gaitzetsi arren, autodeterminazioaren edo independentziaren aldekoa izateak susmagarri bihurtzen zuen edozein herritar.

Pentsamolde nagusi horren barruan kokatu behar dira Egunkaria-ren jarduera eteteko argudio eta ustezko arrazoiak. Egunkariak ez zuen inoiz ezkutatu bere esparru naturala, bere erreferentzia eta irakurleak Euskal Herria osatzen duen lurraldeari zegozkionik. Hau da, euskal hizkuntzak berezkoa duen eremuari: Araba, Bizkaia, Gipuzkoa eta Nafarroa estatu espainiarraren barruan; Lapurdi, Behe Nafarroa eta Zuberoa mugaz beste aldean. Egunkariak sekula ez zuen ukatu hedabide nazionala zenik, ezta nazional adjektiboa euskal lurraldeari zegokionik ere. Baina, era berean, hedabidearen ildo editorialak inoiz ez zuen babestu edo justifikatu ETAren indarkeria. Areago: Egunkaria itxi baino hamabi egun lehenago ETAk Joseba Pagazaurtundua hil zuen Andoainen bertan. Aste horretako igandean indarkeria ez zela bidea idatzi zuen Martxelo Otamendi zuzendariak bere asteroko artikuluan. Handik hamar egunera atxilotu zuen Guardia Zibilak... ETArekin lotuta egotea egotzita!

Gure zuzendariak idatzitako artikulu hura eraman nuen kazeta hetsi ondoren han-hemenka sortutako elkartasun ekitaldietako batera. Valentziako Unibertsitatean emandako hitzaldian ETAren indarkeriari eta hura gaitzesteari buruz Egunkariak zuen iritzia galdetu zidan, tupustean galdetu ere, bertako hedabide bateko kazetari batek. Otamendik idatzi, eta Egunkariak argitaratutako artikulua atera eta irakurri nuen. "Nolaz idatziko du hau ETAren aginduetara dagoen kazetari batek?", galdetu nion kazetariari. Nire azalpenak entzutearekin bat altxatu eta alde egin zuen. "Titularra eman diozu, ez du besterik behar", esan zidan ahapeka nirekin batera mahainguruan parte hartzen ari zen unibertsitateko irakasle batek.

Handik egun batzuetara fax bat bidali zidaten Valentziatik. Kazetari hark idatzitako artikulua zekarren. Titularrak hauxe zioen: "La Universidad con los proetarras de Egunkaria". Testuan era guztietako loreak botatzen zizkigun Valentziako kazetariak. Haren hitzetan, "kazetaria" nintzen -komatxoen artean, nahiz 1985ean lizentziatu nintzen Kazetaritzan, eta 1981. urtetik hainbat hedabidetan jardun dudan, baina horrek ez zion ardura- eta Egunkaria "diario proetarra", "panfleto separatista" eta "libelo próximo a Batasuna" zen. Hedabidea itxi zuen epailea ez zen Juan Del Olmo izan, Guillermo Ruiz Polanco baizik. Merezi luke artikulu hura Kazetaritza eskoletan erakustea: kazetariaren zeregina, haren jarduera etikoa eta informazioaren eta iritziaren arteko diferentzia irakasteko balioko luke, besteak beste. 
Valentziako kazetariaren muturreko pentsaera eta jokaera anekdota bitxi gisa har litezke, baina horrek ez luke errealitatea eta benetan gertatua ahazteko aitzakia izan beharko. Eta errealitatea hauxe izan zen: Espainiako hedabideek, orokorrean, ez zutela modu argian kritikatu hedabide baten itxiera. Batzuek prozeduraren inguruko dudak azaldu zituzten, besterik ez. ETA omen zegoen tartean. Zergatik kritikatu itxiera? Adierazpen askatasunaren kontrako erasoa salatu ez eta, gainera, zalantzan jarri zituzten atxilotutako arduradun eta kazetariek egindako tortura salaketak. Ez dut ahaztuko gai honen inguruan Euskal Telebistako eztabaida saio batean Madrilgo egunkari bateko kazetari eta goi kargudunak zer esan zidan, haren ustez torturarik ez zela egon defendatzeko: "Zuk Martxeloren bertsioa sinesten duzu haren laguna zarelako". Epaiak azaldu zuenez, auzipetuek atxiloaldi inkomunikatuan jasandako tratu txarren eta torturen salaketak eta medikuek detentzio gunean aztertu eta gero osatutako txostenen edukiak bateragarriak izateak "garrantzi berezia" zuen. Gainera, epaileek baieztatu zutenez, ez zen "behar bezalako kontrol judizial eraginkorrik" egon atxilotzearen baldintzen gainean.

Ahots gutxi, oso gutxi altxatu ziren Espainiako komunikabideen esparruan adierazpen askatasunaren kontrako eraso hura gaitzesteko. Turkian gertatua erraz salatzen da, baina zer esan zure mugen barruan halakorik jazotzen bada? Euskal Herritik kanpo Katalunian jaso genuen elkartasun handiena. Bertako gizarteko sektoreek gure aldeko kanpaina bat bultzatu zuten, eta erakunde publiko zein pribatuko ordezkariek besoak zabalik hartu gintuzten. Elkartasun taldeek Egunkaria Endavant egunkari berezia sortu zuten katalan hutsez, eta 30.000 ale banatu zituzten 2003ko Sant Jordi egunean, hedabidea itxi eta hilabetera. Kataluniako kultura, gizarte eta kazetaritza arloko hainbat lagunek euren iritzia plazaratu zuten bertan.

Handik urtebetera, Iñaki Uriak, Egunkaria SAko kontseilari ordezkariak, preso segitzen zuen. Eusko Jaurlaritzako bozeramaile Miren Azkaratek (EAJ) agerraldia egin zuen 2004ko maiatzean, Adierazpen Askatasunaren Nazioarteko Egunaren harira. "Europa osoan guztiz berezia den egoera baten aurrean" geundela azaldu zuen, "demokrazian ez baita ohikoa inongo epaiketarik gabe hedabideak itxiaraztea”. Azkaratek "justizia” eskatu zuen, eta Uria "epairik gabe" preso prebentibo egotea salatu zuen.

Egunkaria ixtea kolpe latza izan zen euskarazko kazetaritzaren kontra, baina ez zuen haren ahotsa betiko mututu. Biharamunean Egunero kazeta argitaratu zuten hedabideko kazetariek. Hedabide berriaren lehen aleak titular hau zuen azalean: Itxia, baina ez isildua. Egunerok lau hilabetez argitaratzen segitu zuen, harik eta 2003ko ekainaren 21ean Berria sortu zen arte. Egoera larria izan zen, mina eman ziguten, baina ezin izan zuten gure boza isildu. Hamabost urte igaro dira goizaldeko dei horretatik. Hamabost urteko bidegabekeriak bere horretan dirau, ez baitute egindako kaltea erreparatu. Hala ere, ezin izan dute gure ametsa zapuztu: euskarazko egunkariak bizirik segitzen du.

Jose Mari Pastor. Euskal Herriko Unibertsitateko Gizarte eta Komunikazio Zientzien Fakultateko Kazetaritza Saileko irakaslea da. 80ko hamarkadaren hasieratik orain arte hainbat hedabidetan lan egin edo kolaboratu du, hala nola Anaitasuna, Egunon, EITB, Egunkaria eta Berria, besteak beste. 
Ámbitos. Revista Internacional de Comunicación, n.40, edición de primavera, 2018. 